
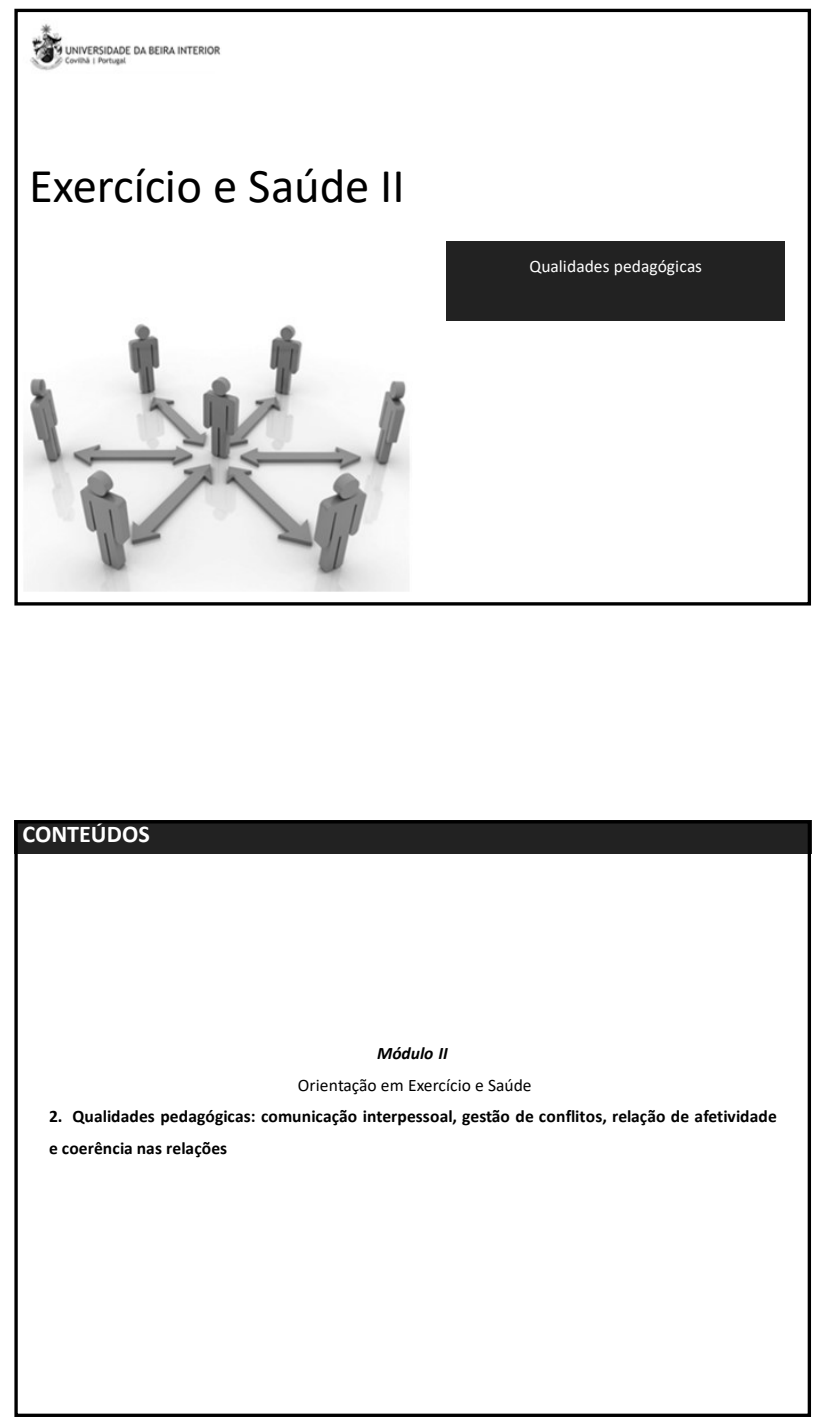

\title{
QUALIDADES PEDAGOGICAS
}

Conjunto de características e competências a desenvolver para desempenhar de forma ótima qualquer trabalho que envolva relação com os outros

Inteligência emocional

(reconhecer e gerir os estados emocionais

\begin{tabular}{|c|c|}
\hline $\begin{array}{l}\text { - Capacidades internas: } \\
\text { - Ser consciente } \\
\text { - Controlar as emoções e sentimentos } \\
\text { - Autoconfiança } \\
\text { - Entusiasmo e motivação }\end{array}$ & $\begin{array}{l}\text { - Capacidade interpessoais: } \\
\text { - Assertividade (firme mas flexível) } \\
\text { - Escuta ativa } \\
\text { - Empatia } \\
\text { - Relação pessoal (?) }\end{array}$ \\
\hline - Segurança e predisposição & \\
\hline
\end{tabular}




\section{QUALIDADES PEDAGOGICAS}

Comunicação interpessoal

Gestão de conflitos

Relação de afetividade

Coerência nas relações

\section{QUALIDADES PEDAGÓGICAS}

Comunicação interpessoal

Forma de expressar quem somos, como somos, o que sentimos, o que desejamos e o que esperamos dos outros.

Perceber as necessidades e emoções das pessoas com que interagimos, em torno das quais se desenvolvem relações

A) Comunicacão verbal $-30 \%$ do que transmitimos ou recolhemos Clareza e objetividade

Termos e linguagem adequados

B) Comunicação não verbal pode chegar até $70 \%$ Contacto visual

Contacto
Tom Voz

Gestos e atitude postural

Aparência, imagem e testemunho

\section{QUALIDADES PEDAGOGICAS}

\section{Gestão de conflitos}

Divergência de perspetivas => tensão por pelo menos uma das partes envolvidas numa determinada interaça

Competição

Próprios interesses à custa dos interesses do outro, ou convencer que nosso julgamento é correto

Quando usar:

Acão imediata dada a emergência

Uso das nossas responsabilidades, as quais ninguém poderá assumi 


\section{Gestão de conflitos}

Divergência de perspetivas $=>$ tensão por pelo menos uma das partes envolvidas numa determinada interação

Acomodação

Interesses dos outros, negligenciando os próprios

Quando usar:

Manter relação de confiança

Questão de personalidade, não pondo em causa a competência responsabilidade

\section{QUALIDADES PEDAGOGICAS}

\section{Gestão de conflitos}

Divergência de perspetivas $=>$ tensão por pelo menos uma das partes envolvidas numa determinada interação

\section{Compromisso}

Satisfazer ambas as partes - objetivo/acordo parcial

Quando usar:

Melhor consenso e acordo do que nenhum (objetivos/metas de treino...)

Pontos de vista muito diferentes

\section{QUALIDADES PEDAGOGICAS}

\section{Gestão de conflitos}

Divergência de perspetivas => tensão por pelo menos uma das partes envolvidas numa determinada interaço

Colaboração

Satisfazer completamente ambas as parte

Quando usar:

Objetivos comun

Necessidade de consenso e cooperação para progressão

IMPLICA: tempo e dificuldade em partilhar e assumir responsabilidades 
Divergência de perspetivas $=>$ tensão por pelo menos uma das partes envolvidas numa determinada interação

Evitamento

Ignorar ou negligenciar os interesses de ambas as partes

Quando usar:

Não se reúnem todos dados ou informação para poder optar Nossa ação não tem qualquer efeito

\section{QUALIDADES PEDAGOGICAS}

\section{Relação de afetividade}

Relação de proximidade e de confiança

Interesse sincero pelo cliente (utilizar o nome)

Desenvolver empatia, procura afinidades

Reconhecimento, valorização, formas de motivação e de aproximação

\section{QUALIDADES PEDAGOGICAS}

Coerência nas relações

Ser um "bom líder" em todo o processo

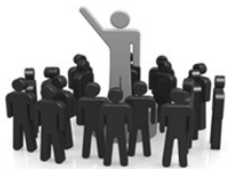




\section{QUALIDADES PEDAGOGICAS}

1. Demonstrar interesse nos clientes - razões da sua presença e quais os seus objetivos Ser entusiástico e motivante na instrução e orientação

Desenvolver uma relação pessoal com cada cliente: saber e tratar pelo nome Estar atento às razões individuais que originam a procura do programa

Acompanhar de início os clientes, sobretudo quando há ausências sem causa.

Praticar e dominar as modalidades orientadas (postura/aparência) $E O F$

Relembrar e assinalar datas especiais (aniversário)

Acompanhar devidamente problemas ósseos e musculares

Aconselhar os clientes relativamente aos vestuários e calçado

10. Transmitir sobretudo informaç̃̃es e o conhecimento prático

11. Providenciar folhetos e informação pertinente sobre tópicos de interesse

12. Encorajar um potencial cliente a experimentar determinada târefa/atividade

13. Dispor de área e tempo para aconselhamento particular

14. Motivar, elogiando e através de feedbacks construtivos e positivos. N COLLECE

15. Incentivar a participação em eventos gerais de atividade física, mostrando interesse e $/$ : entusiasmo em participar com os clientes

\section{QUALIDADES PEDAGOGICAS}

Casos reais...

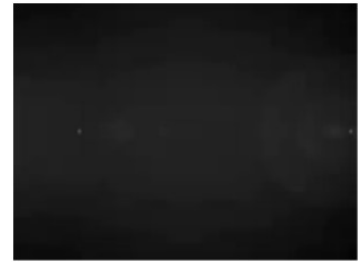

a) O cliente colocar peso e carga excesso;

b) Distração do orientador

c) Descuido do dono das instalaç̃es

d) Do orientador e do dono das instalações

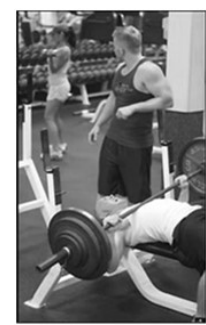

\section{QUALIDADES PEDAGOGICAS}

SUPERVISÃO E INSTRUÇÃO
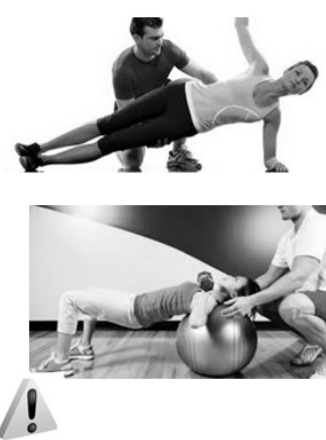

- Permanecer

com o cliente continuamente durante a sessão supervisão

- Ensinar a correta execução e uso adequado do equipamento

- Vigiar sinais e síntomas de esforço excessivo

- Recomendações sobre segurança e exercícios no caso de populações especiais

- Trabalho com 2 clientes: alternar exercícios/situações que requerem supervisão direta 


\begin{tabular}{|c|c|c|}
\hline AVALIAÇÃo & \multirow[b]{2}{*}{ TREINO } & CONDICÃO \\
\hline MOTIVAÇÃo & & SICA E SAÚDE \\
\hline INSTRUÇÃO & $\rightleftarrows$ & \\
\hline & \multicolumn{2}{|r|}{ Encaminhar } \\
\hline ACONSELHAMENTO & \multirow{2}{*}{$\begin{array}{l}\text { PROFISSIONAL de } \\
\text { SAÚDE } \\
\text { INTITULADO }\end{array}$} & \\
\hline DIAGNÓSTICO & & \\
\hline TRATAMENTO & & \\
\hline
\end{tabular}

\section{Bibliografia a consultar}

Pescatello, L. S., \& American College of Sports Medicine. (2014). ACSM's guidelines for exercise testing and prescription. Philadelphia: Wolters Kluwer/Lippincott Williams \& Wilkin

Ferguson, B. (2014). ACSM's Guidelines for Exercise Testing and Prescription 9th Ed. 2014. The Journal of the Canadian Chiropractic Association, $58(3), 328$

Garber, C. E., Blissmer, B., Deschenes, M. R., Franklin, B. A., Lamonte, M. J., Lee, I. M. Nieman, D. C., ... American College of Sports Medicine. (January 01, 2011). American Colleg of Sports. Medicine position stand. Quantisy and quality of exerise for developing and maintain adults: g $1334-59$

American College of Sports Medicine (2010). “ACSM's Guidelines for Exercise Testing and Prescription". 8ª Ediçã̃o 